\title{
HYDROTHERAPY IN HEART FAILURE: A CASE REPORT
}

\author{
doi: $10.1590 / \mathbf{S 1 8 0 7 - 5 9 3 2 2 0 0 9 0 0 0 8 0 0 0 2 0}$
}

Vitor Oliveira Carvalho, ${ }^{\mathrm{I}, \mathrm{II}}$ Edimar Alcides Bocchi, ${ }^{\mathrm{I}, \mathrm{II}}$ Guilherme Veiga Guimarães ${ }^{\mathrm{IIII}}$

\section{BACKGROUND}

Heart failure is considered to be the last stage of heart disease and a significant cause of morbidity and mortality worldwide. ${ }^{1,2,3}$ It is characterized by the persistent activation of the neurohormonal system, ${ }^{4}$ endothelial dysfunction, ${ }^{5}$ exercise intolerance, ${ }^{6,7,89}$ high mortality ${ }^{10}$ and a poor quality of life. ${ }^{11}$

Exercise training has been strongly recommended as a safe and important tool for the non-pharmacological treatment of heart failure. Exercise training improves exercise capacity, ${ }^{12,13}$ quality of life, ${ }^{14}$ endothelial dysfunction, ${ }^{15}$ skeletal muscle oxidative capacity, ${ }^{16}$ the cathecolamine plasma level ${ }^{17}$ and the autonomic and ventilatory responses. ${ }^{18}$ In heart failure patients, designing an appropriate aerobic exercise routine is crucial for obtaining both an increase in exercise capacity and the reasonable control of exercise-related risks. ${ }^{1,6}$

Hydrotherapy (i.e., exercise in warm water) had been considered potentially dangerous in heart failure patients due to the increased venous return caused by the hydrostatic pressure. However, it is now known that cardiac function actually improves during water immersion due to the increase in early diastolic filling and decrease in heart rate, resulting in improvements in stroke volume and ejection fraction. ${ }^{19}$ Studies with sauna therapy (i.e., warming) have demonstrated important improvements in neurohormonal attenuation and exercise status in heart failure patients. These data suggest that hydrotherapy is a good potential treatment for heart failure patients. However, few studies are available,

${ }^{\text {I } U n i d a d e ~ C l i ́ n i c a ~ d e ~ I n s u f i c i e ̂ n c i a ~ C a r d i ́ a c a ~ e ~ T r a n s p l a n t e ~ d o ~ I n s t i t u t o ~ d o ~}$ Coração do Hospital das Clínicas da Faculdade de Medicina da USP (InCor HC-FMUSP) - São Paulo/SP, Brazil.

II Laboratório de Atividade Física e Saúde do Centro de Práticas Esportivas da Universidade de São Paulo (LATIS-CEPEUSP) - São Paulo/SP, Brazil. Email: vitor.carvalho@usp.br and none have compared conventional rehabilitation to hydrotherapy. ${ }^{20}$

This study was partially supported by "Coordenação de Aperfeiçoamento de Pessoal de Nível Superior".

\section{CASE REPORT}

A 51-year-old male heart failure patient (ischemic etiology with $40 \%$ left ventricular ejection fraction) was recruited from a cardiology hospital to this rehabilitation program (Table 1). This patient underwent 24 exercise sessions in a $22-24^{\circ} \mathrm{C}$ temperature-controlled gym (conventional exercises) between May and July 2007. After the exercise training program, this patient was invited to continue in our rehabilitation program but opted out. After 6 months, the patient returned to our program to continue the exercise program, and we assigned him to hydrotherapy. Between January and March 2008, he had 24 more exercise sessions in a $30-31^{\circ} \mathrm{C}$ temperaturecontrolled swimming pool (hydrotherapy). The exercise training protocol was almost the same for both methods: 5 minutes of warm up exercises (stretching), 30 minutes of aerobic exercise training ( $90 \%$ of ventilatory threshold), 25 minutes of strength exercises (lower and upper limbs) and 5 minutes of cool down exercises (stretching). A treadmill (Max 1; Marquette Electronics; Milwaukee, WI, USA) cardiopulmonary exercise test (Vmax 229 model, SensorMedics, Yorba Linda, CA, USA), 24-hour ambulatory blood pressure measurement (Space Labs Redmond, Wash, USA), New York Heart Association functional classification and a Minnesota Living With Heart Failure Questionnaire were performed before and after the exercise training protocols (the cardiopulmonary exercise test was performed 2 days prior to the other evaluations). The medications were not changed during the protocols $(150 \mathrm{mg} /$ day Carvedilol, 100 mg/day Losartan, 40 mg/day Furosemide, 25 mg/day 
Table 1 - Patient data before and after exercise training

\begin{tabular}{|c|c|c|c|c|}
\hline & $\begin{array}{l}\text { Conventional } \\
\text { (pre-training) }\end{array}$ & $\begin{array}{l}\text { Conventional } \\
\text { (post-training) }\end{array}$ & $\begin{array}{l}\text { Hydrotherapy } \\
\text { (pre-training) }\end{array}$ & $\begin{array}{l}\text { Hydrotherapy } \\
\text { (post-training) }\end{array}$ \\
\hline BMI $\left(\mathrm{kg} / \mathrm{m}^{2}\right)$ & 36.7 & 37.1 & 38.8 & 37.5 \\
\hline Waist (cm) & 120 & 119 & 123 & 121 \\
\hline Hip (cm) & 110 & 110 & 121 & 117 \\
\hline Peak VO ${ }_{2}\left(\mathrm{mLO}_{2} \cdot \mathrm{kg}^{-1} \cdot \mathrm{min}^{-1}\right)$ & 21.5 & 28.7 & 16.5 & 26.9 \\
\hline $\mathrm{VO}_{2} \mathrm{AT}\left(\mathrm{mLO}_{2} \cdot \mathrm{kg}^{-1} \cdot \mathrm{min}^{-1}\right)$ & 12.8 & 13.3 & 9.0 & 12.5 \\
\hline $\mathrm{VO}_{2} \mathrm{VT}\left(\mathrm{mLO}_{2} \cdot \mathrm{kg}^{-1} \cdot \mathrm{min}^{-1}\right)$ & 17.3 & 21.7 & 16.1 & 20.5 \\
\hline $\mathrm{VE} / \mathrm{VCO}_{2}$ slope & 28.7 & 27.5 & 33.3 & 24.5 \\
\hline RER & 1.05 & 1.04 & 1.04 & 1.07 \\
\hline Time (exercise test) & 17 & 19 & 14 & 16 \\
\hline NYHA & 2 & 1 & 3 & 1 \\
\hline MLHFQ & 51 & 49 & 68 & 26 \\
\hline SBP 24 hours (mmHg) & 118 & 117 & 130 & 125 \\
\hline DBP 24 hours (mmHg) & 63 & 67 & 70 & 66 \\
\hline HR 24 hours (bpm) & 69 & 76 & 91 & 69 \\
\hline SBP daytime $(\mathrm{mmHg})$ & 124 & 117 & 137 & 127 \\
\hline DBP daytime (mmHg) & 67 & 67 & 74 & 69 \\
\hline HR daytime (bpm) & 69 & 78 & 94 & 67 \\
\hline SBP nighttime $(\mathrm{mmHg})$ & 108 & 118 & 116 & 122 \\
\hline DBP nighttime (mmHg) & 55 & 68 & 62 & 61 \\
\hline HR nighttime (bpm) & 69 & 72 & 85 & 73 \\
\hline
\end{tabular}

$\mathrm{VO}_{2}$, Oxygen consumption; RER, Respiratory exchange ratio; NYHA, New York Heart Association Functional Class; MLHFQ, Minnesota Living with Heart Failure Questionnaire; SBP, Systolic blood pressure; DBP, Diastolic blood pressure; HR, heart rate.

Spironolactone and $0.25 \mathrm{mg} /$ day Digoxin). This protocol was approved by the ethical committee of our institution (number 1107/05).

\section{DISCUSSION}

Exercise training is a well-established non-pharmacological treatment for patients with heart failure. Hydrotherapy is a new and well-tolerated method of exercise rehabilitation for heart failure patients. It is an alternative for elderly patients and patients with impaired mobility. ${ }^{21}$ The patient in this case study did not have any orthopedic problems despite his high body mass index.

Studies with sauna baths have shown that they can lead to great improvements in heart failure by attenuating the neurohormonal system..$^{21,22}$ It is possible that hydrotherapy (i.e., exercise in a warm swimming pool) could provide the same beneficial effects of conventional exercise training and warming while also attenuating the neurohormonal system more significantly. Therefore, we expected the patient to improve more with hydrotherapy than with conventional exercise.
In this case, hydrotherapy was an effective method of cardiovascular rehabilitation and a safe alternative to conventional exercise. This is the first report in which a patient has performed both forms of exercise. The patient's peak and anaerobic threshold oxygen consumption, VE/ $\mathrm{VCO}_{2}$ slope, Minnesota living with heart failure quality of life score, body mass index, 24-hour ambulatory blood pressure and waist and hip circumference improved with both methods of exercise rehabilitation, but the improvements were more pronounced with hydrotherapy. The patient's peak and anaerobic threshold oxygen consumption showed an increase of $7.2 \mathrm{mLO} \cdot \mathrm{kg}^{-1} \cdot \mathrm{min}^{-1}$ during regular exercise training versus $10.4 \mathrm{mLO}_{2} \cdot \mathrm{kg}^{-1}$. $\min ^{-1}$ with hydrotherapy and an increase of $0.5 \mathrm{mLO}_{2} \cdot \mathrm{kg}^{-1}$. $\min ^{-1}$ with regular training versus $3.5 \mathrm{mLO}_{2} \cdot \mathrm{kg}^{-1} \cdot \mathrm{min}^{-1}$ with hydrotherapy, respectively. His $\mathrm{VE} / \mathrm{VCO}_{2}$ slope decreased by 1.2 with regular training, while it decreased to 8.8 with hydrotherapy. The Minnesota living with heart failure quality of life score decreased by 2 with regular training and by 42 with hydrotherapy. The patient's body mass index increased by $0.4 \mathrm{~kg} / \mathrm{m}^{2}$ with regular training, while it decreased by 1.3 $\mathrm{kg} / \mathrm{m}^{2}$ with hydrotherapy. His mean 24-hour systolic blood 
pressure showed a $1 \mathrm{~cm} \mathrm{H_{2 }} \mathrm{O}$ decrease with regular training, while it decreased by $5 \mathrm{~cm} \mathrm{H}_{2} \mathrm{O}$ with hydrotherapy. On the other hand, his mean diastolic blood pressure was unchanged by regular training while it decreased by $5 \mathrm{~cm} \mathrm{H}_{2} \mathrm{O}$ with hydrotherapy. The patient's waist circumference showed a decrease of $1 \mathrm{~cm}$ with regular training and a decrease of $2 \mathrm{~cm}$ with hydrotherapy, while his hip circumference was unchanged by regular training but showed a $4 \mathrm{~cm}$ decrease with hydrotherapy.

Exercise intolerance (low peak oxygen consumption) and poor quality of life have been negatively correlated to neurohormonal activity in heart failure patients. ${ }^{23}$ Some clinical exams, such as the 24-hour ambulatory blood pressure, can detect the exacerbated neurohormonal activity seen in heart failure. ${ }^{24}$ These clinical data reflect the stronger neurohormonal attenuation provided by hydrotherapy. Importantly, signs and symptoms of exercise intolerance were not observed during either exercise regimen.

\section{CONCLUSION}

In this case report, we demonstrate that hydrotherapy is an effective method of cardiovascular rehabilitation and can be a safe alternative to conventional exercise.

\section{REFERENCES}

1. Working Group on Cardiac Rehabilitation \& Excercise Physiology and Working Group on Heart Failure of the European Society of Cardiology. Eur Heart J. 2001;22:37-45.

2. Bocchi EA, Carvalho VO, Guimaraes GV. Inverse correlation between testosterone and ventricle ejection fraction, hemodynamics and exercise capacity in heart failure patients with erectile dysfunction. Int Braz J Urol. 2008:34:302-10.

3. Guimaraes GV, D'Avila MV, Silva MS, Ciolac EG, Carvalho VO, Bocch EA. A cutoff point for peak oxygen consumption in the prognosis of heart failure patients withbeta-blocker therapy, Int J Cardiol 2009, doi:10.1016/j.ijcard.2009.05.001

4. Chizzola PR, Gonçalves de Freitas HF, Marinho NV, Mansur JA, Meneghetti JC, Bocchi EA. The effect of beta-adrenergic receptor antagonism in cardiac sympathetic neuronal remodeling in patients with heart failure. Int J Cardiol. 2006;106:29-34.

5. Maruo T, Nakatani S, Kanzaki H, Kakuchi H, Yamagishi M, Kitakaze $\mathrm{M}$, et al. Circadian variation of endothelial function in idiopathic dilated cardiomyopathy. Am J Cardiol 2006; 97:699-702.

6. Ades PA, Savage PD, Brawner CA, Lyon CE, Ehrman JK, Bunn JY, et al Aerobic capacity in patients entering cardiac rehabilitation. Circulation. 2006;133:2706-12.

7. Carvalho VO, Guimarães GV, Bocchi EA. The relationship between heart rate reserve and oxygen uptake reserve in heart failure patients on optimized and non-optmized beta-blocker therapy. Clinics.2008;63:725-30.

8. Carvalho VO, Guimarães GV, Ciolac EG, Bocchi EA. Heart rate dynamics during a treadmill cardiopulmonary exercise test in optimized beta-blocked heart failure patients. Clinics. 2008 ;63:479-82.

9. Carvalho VO, Alves RXR, Bochi EA, Guimarães GV. Heart rate dynamic during an exercise test in heart failure patients with different sensibilities of the carvedilol therapy. Int J Cardiol 2009: doi:10.1016/j. ijcard.2008.11.140.
10. Bocchi EA, Cruz F, Guimarães G, Moreira LFP, Issa VS, Ferreira SMA, et al. Long-term prospective, randomized, controlled study using repetitive education at six-month intervals and monitoring for adherence in heart failure outpatients. The REMADHE study. Circ Heart Fail. 2008;1:115-24.

11. Carvalho VO, Guimarães GV, Carrara D, Bacal F, Bocchi EA. Validation of the Portuguese Version of the Minnesota Living with Heart Failure Questionnaire. Arq Bras Cardiol 2009;93:36-41.

12. Keteyian SJ, Levine AB, Brawner CA, Kataoka T, Rogers FJ, Schairer $\mathrm{JR}$, et al. Exercise training in patients with heart failure. A randomized, controlled trial. Ann Intern Med. 1996;124:1051-7.

13. Carvalho VO, Ciolac EG, Guimarães GV, Bocchi EA. Effect of Exercise Training on 24-Hour Ambulatory Blood Pressure Monitoring in Heart Failure Patients. Congest Heart Fail. 2009;15:176-80.

14. Belardinelli R, Giorgiou D, Cianci G, Purcaro A. Randomized, controlled trial of long-term moderate exercise training in chronic heart failure: effects on functional capacity, quality of life, and clinical outcome. Circulation. 1999;99:1173-82.

15. Hornig B, Maier V, Drexler H. Physical training improves endothelial function in patients with chronic heart failure. Circulation. 1996;93:2104.

16. Hambrecht R, Niebauer J, Fiehn E, Kälberer B, Offner B, Hauer K, et al. Physical training in patients with stable chronic heart failure: effects on cardiorespiratory fitness and ultrastructural abnormalities of leg muscles. J Am Coll Cardiol. 1995;25:1239-49.

17. Hambrecht R, Gielen S, Linke A, Fiehn E, Yu J, Walther C, et al. Effects of exercise training on left ventricular function and peripheral resistance in patients with chronic heart failure: A randomized trial. JAMA. 2000;283:3095-101.

18. Piepoli M, Clark AL, Volterrani M, Adamopoulos S, Sleight P, Coats AJ. Contribution of muscle afferents to the hemodynamic, autonomic, and ventilatory responses to exercise in patients with chronic heart failure: effects of physical training. Circulation. 1996;93:940-52. 
19. Cider A, Sveälv BG, Täng MS, Schaufelberger M, Andersson B. Immersion in warm water induces improvement in cardiac function in patients with chronic heart failure. Eur J Heart Fail. 2006;8:308-13.

20. Cider A, Schaufelberger M, Sunnerhagen KS, Andersson B. Hydrotherapy--a new approach to improve function in the older patient with chronic heart failure. Eur J Heart Fail. 2003;5:527-35.

21. Miyamoto H, Kai H, Nakaura H, Osada K, Mizuta Y, Matsumoto A, et al. Safety and Efficacy of Repeated Sauna Bathing in Patients With Chronic Systolic Heart Failure: A Preliminary Report. J Card Fail. 2005;11:432-6.
22. Kihara T, Biro S, Imamura M, Yoshifuku S, Takasaki K, Ikeda Y, et al. Repeated Sauna Treatment Improves Vascular Endothelial and Cardiac Function in Patients With Chronic Heart Failure. J Am Coll Cardiol. 2002;39:754-9.

23. von Haehling S, Lainscak M, Springer J, Anker SD. Cardiac cachexia: A systematic overview. Pharmacol Ther. 2009;121:227-52.

24. Ingelsson E, Björklund-Bodegård K, Lind L, Arnlöv J, Sundström J. Diurnal blood pressure pattern and risk of congestive heart failure. JAMA. 2006;28:2859-66. 